\title{
Novel Insights on Plant Extracts to Prevent and Treat Recurrent Urinary Tract Infections
}

\author{
Adriana Mirela Tache, Laura Dorina Dinu * and Emanuel Vamanu *(D)
}

check for updates

Citation: Tache, A.M.; Dinu, L.D.; Vamanu, E. Novel Insights on Plant Extracts to Prevent and Treat Recurrent Urinary Tract Infections. Appl. Sci. 2022, 12, 2635. https://doi.org/10.3390/ app12052635

Academic Editor: Akikazu Sakudo

Received: 13 January 2022

Accepted: 2 March 2022

Published: 3 March 2022

Publisher's Note: MDPI stays neutral with regard to jurisdictional claims in published maps and institutional affiliations.

Copyright: (C) 2022 by the authors. Licensee MDPI, Basel, Switzerland. This article is an open access article distributed under the terms and conditions of the Creative Commons Attribution (CC BY) license (https:// creativecommons.org/licenses/by/ $4.0 /)$.
Faculty of Biotechnology, University of Agricultural Sciences and Veterinary Medicine, 011464 Bucharest, Romania; tacheadriana95@yahoo.com

* Correspondence: laura.dinu@biotehnologii.usamv.ro (L.D.D.); email@emanuelvamanu.ro (E.V.)

Abstract: Urinary tract infections (UTI) represent one of the most widespread infections, and frequent recurrent episodes, induced mostly by uropathogenic Escherichia coli, make them increasingly difficult to treat. Long-term antibiotic therapy is an effective approach to treat recurrent UTI but generates adverse effects, including the emergence of pathogenic strains resistant to the vast majority of antibiotics. These drawbacks have enhanced the interest toward new alternatives based on plant extracts to prevent and treat recurrent UTI, especially in a synergistic antibiotic approach. Therefore, this review highlights the potential of some medicinal plants to be used in the management of recurrent UTI, including plants that have been approved for the treatment of urinary infections and promising, but less studied, plant candidates with proven anti-uropathogenic activity. Pomegranate (Punica granatum L.), black chokeberry (Aronia melanocarpa Michx.), and cornelian cherry (Cornus mas L.) have great potential to be used for prevention or in a combined antibiotic therapy to cure UTI, but more studies and clinical trials in specific population groups are required. Further progress in developing plant-based products to cure rUTI will be supported by advances in UTI pathogenesis and human-based models for a better understanding of their pharmacological activities.

Keywords: uropathogenic; herbal medicines; plant extract; bioactive molecules

\section{Introduction}

Urinary tract infections, abbreviated UTI, frequently occur in the urinary tract, affecting up to 150 million people/year worldwide [1,2]. Recurrent UTI (rUTI) is more frequent in young females, but it has been estimated that up to $50 \%$ of women experience a UTI at least once in their lives [3,4]. A notable proportion of patients who develop UTI have no discernible causes. However, UTI is mainly associated with patients with detected urinary tract abnormalities, suppressed immune systems, long-term catheter use, and recent urinary procedures. A lot of recent studies suggest a genetic predisposition to the recurrent symptomatic UTI. Numerous genes seem to contribute and have been strongly associated with UTI-prone patients [2,5].

rUTI is defined as two or more episodes of symptomatic lower UTI in the last six months or three or more episodes in the past 12 months, based on the European Union guidelines for rUTI in adults. Uropathogenic E. coli (UPEC) is the most common bacterial agent for all types of UTI and is responsible for 70-90\% of urinary infections, followed by K. pneumoniae in uncomplicated UTI and E. spp. in complicated UTI [6]. E. coli belongs to the Enterobacteriaceae family of bacteria. Despite being one of the most well documented and studied bacterial species globally, it continues to pose a constant threat to human health, particularly in medical settings $[7,8]$.

Prophylactic low-dose antimicrobial therapy represents the current gold standard practice. First-line antibiotics, such as trimethoprim, nitrofurantoin, amoxicillin, and cefalexin are recommended, while second-line quinolones should be considered for more severe infections (NHS Guidelines). The continuous antibiotic prophylaxis reduces the 
rate of UTI but induces adverse effects, including vaginal and oral candidiasis, and gastrointestinal symptoms, and the spread of antibiotic resistance. Following an antibiotic resistance index assessment, these infections have become increasingly difficult to treat since the mid-2000s [9]. This emphasizes the need for new treatment regimens against urinary infections with innovation by introducing alternative therapies based on herbal extracts, nanoparticles, and dietary supplements [10]. Plant remedies are a natural option for the long-term treatment of rUTI, especially in a synergistic antibiotic approach, as they have antimicrobial effects, can reduce different symptoms (e.g., anti-inflammatory, antipyretic, and analgesic effects), and help decrease adverse antibiotic effects. Moreover, they can be a prophylactic treatment to prevent rUTI for patients that have experienced urinary infection for years and in precision medicine.

This review aims to present the current knowledge about promising plant extracts, including candidate plant-based products that can be applied in the management of the rUTI as prophylactic or treatment therapy, and future directions for research are highlighted.

\section{Pathogenesis of rUTI}

The most common risk factors for UTI are female anatomy, age, sexual, birth control activity, and menopause (Figure 1). However, other risk factors, such as abnormalities and blockages in the urinary tract, catheter, or recent urinary procedures should be considered [11]. The studies on hereditary UTI started when it was noticed that the infection tends to be clustered in specific individuals and is relevant among females with relatives that suffer from recurring UTI. The candidate genes determining human/animal UTI susceptibility have been identified starting from the early 1980s using various genetic and immunological tools [12]. These studies concluded that increased susceptibility to UTI is a complex heritable trait with numerous genes that seem to contribute to the UTI-prone phenotype. These genes are involved in antimicrobial defense [13]. The host resistance to recurrent UTI relies strongly on the pathways that signal the innate immune system and the genes that control those pathways. In contrast, different immune variants can exacerbate acute and chronic infection or be protective $[12,14]$.

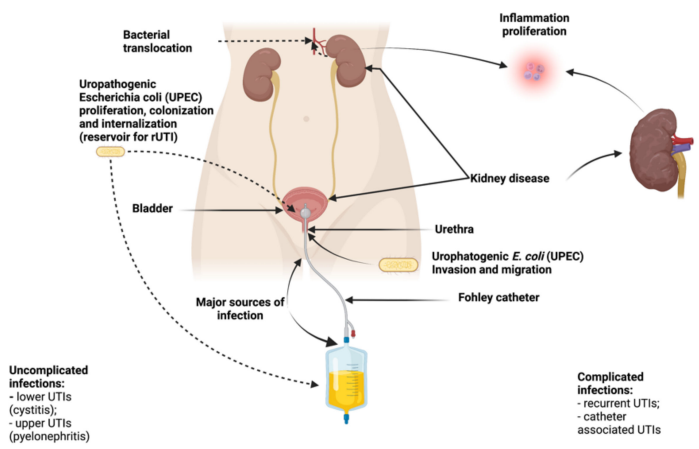

Figure 1. The pathogenesis of rUTI and their effects on human urinary system homeostasis. The major sources of infection are intestinal, perineal, vaginal, and preputial microflora, then E. coli (UPEC) migrate and invade the bladder tissue where they form biofilm and internalize. The migration of E. coli (UPEC) affects the kidney's normal functions as an effect of inflammation proliferation. The persistence of the inflammatory process at this level could determine bacterial translocation. The picture was created with the Biorender app.

Based on the current knowledge about the pathogenesis of rUTI, there are three main components involved: pathogen virulence, the host's defense mechanism, and the environment [15]. The etiology of UTI includes Gram-positive and Gram-negative bacteria and fungi, but UPEC accounts for a significant proportion of rUTI [6]. Uropathogenic E. coli strains from reservoirs (intestinal, perineal, vagina, and preputial microflora) invade the urinary tract. Bacterial virulence factors (e.g., flagella/pili, extracellular polysaccharides, toxins, and enzymes) may contribute to UTI recurrence [2,14]. The bacterial urogenital 
mucosa attachment activates a cascade of signaling molecules in the host from innate immune responses that stimulate cytokine release resulting in an inflammatory response and symptoms. In response, bacteria produce molecules that specifically inhibit the signaling pathways and use toxins to kill the mucosal barrier cells and enter the bloodstream in the acute phase of infection. Thus, the severity of a UTI depends on the innate defensive response of the host and the virulence of the infecting agents. In the case of rUTI, bacteria form biofilm. Moreover, they can persist in quiescent communities, surviving the immune response and resisting antibiotic attacks. Recurrent urinary tract infections are based on the same pathogenic microorganism that underwent the initial condition, E. coli strains that use the reservoirs associated with the host in the gastrointestinal tract and bladder tissue to repopulate/reinforce the host [9]. In human anatomy, E. coli is primarily found in the gastrointestinal tract. The proximity of the urethra to the anus, particularly in female patients, makes E. coli a significant contributor or activator in most catheter-associated urinary tract infections (CAUTI) for intermittent catheter users [7]. Another cause of rUTI is bladder dysbiosis, an alteration of the urinary microbiota by strains from reservoirs that compete with the natural microbial community, and uropathogens can become dominant. Antibiotic prophylactic treatment is another critical factor affecting rUTI because it favors the development of multidrug-resistant (MDR) uropathogenic bacteria, which are more virulent and persistent $[2,14]$.

\section{Classification of Causes in Cases of UTI}

The following stages of the evolution of a urinary tract infection were highlighted due to the morphology of the patient's urinary tract and past incidences of the disease [16]:

- Uncomplicated Infection: It can be defined as the infection of a relatively healthy urinary tract patient who responds to antibiotic treatment;

- Complicated Infection: It occurs mainly in people with an abnormal urinary tract, which are often obstructed by stones or bladder-ureter reflux;

- Isolated Infections: Represent the mother infection or the infection that appears at an interval of six months, without any connection between the two episodes;

- Unresolved Infection: It is the opposite of uncomplicated infection; it does not respond to antibiotic treatment;

- Reinfection/Recurrence: Reinfection is the last stage of the evolution of urinary tract infections, described as a persistent bacterial infection. At this stage, the individual is reinfected with the same pathogen two weeks after treating a urinary tract infection.

\section{In Vitro Urinary Tract Models}

To develop new plant-based treatment strategies, it is imperious to improve our knowledge about UTI pathogenesis using different model systems that will provide practical information about the host-pathogen interaction and unique aspects of the urinary tract environment [17]. The mechanism of rUTI is complex, and over the last decades, several hypotheses have emerged based on animal models or advanced human cell-based in vitro models. A recent exhaustive review discussed the importance of model systems in revealing the crucial insights about UTI pathogenesis, including their strengths and limitations [2]. Further progress in improving the plant-based strategies to cure rUTI will be supported by advances in human-based models that are more accurate and controllable than animal models and can reveal bottleneck points of UTI pathogenesis $[18,19]$.

In general, in vitro urinary tract infection models are based on the cells in static culture; however, the intricacy and antibiotic resistance of these infections have necessitated the need to expand these studies to include the characteristics of the bladder's physiological conditions (e.g., urine and fluid flow). Advanced in vitro human cell-based models that provide a complementary platform (along with animals) for drug detection and alternative treatment strategies are directly proportional to studies on the complexity of recurrent urinary tract infections [2]. 
Some models were based on a virulent bacterium colonizing a bladder in vitro at the laboratory level. These models were created based on research about preventing symptomatic urinary tract infection caused by aggressive bacteria by colonizing the bladder with strains that cause asymptomatic bacteriuria $(\mathrm{ABU})$, which are less virulent bacteria. These asymptomatic E. coli strains were created by comparing isolated ABUs from diabetic patients in terms of their virulence-associated phenotypes and virulence in an in vitro model with murine sepsis (from laboratory rats) and the content of their genome [20,21].

Generalized Lotka-Volterra modeling (gLVM) has revealed the protective role of two taxonomic classes of bacteria, Actinobacteria and Bacteroides, which appear to suppress pathogen growth. For longitudinal data, the original BEEM approach (biomass estimation and model inference with a maximizing of expectancies) was utilized to simulate the microbiota shift after $24 \mathrm{~h}$ of antibiotic therapy [22].

These models are highly desirable because of their advantages compared to animal models and their potential to study a wide variety of conditions, such as UTI in bladder cancer, tissue regeneration/transplantation, and the effect of xenobiotics that come into contact with the urine, in vitro in the human bladder environment and reconstitution of the urothelium (or even organ) [2,23].

While the procedure can preserve a precise 3D cell architecture, layering, and differentiation, it is time-consuming, requires quick access to fresh tissue, and may show variability between samples [20]. There is also a growing chance that stromal and urothelial cells will come into contact with undesired combinations during cultivation, with stromal cells outgrowing the urothelium $[24,25]$.

Because the existing experimental models have flaws and only provide partial results, new tactics have been created, including new experimental 3D bladder models that strive to reproduce/imitate the human urothelium employing stem cells or stem cells that have been propagated, expanded, and stratified/differentiated. Some are even protected by patents [26].

\subsection{In Vitro Catheterization Model (IVCM)}

The research was carried out in the Laboratory of Pharmaceutical Biotechnologies of the Faculty of Biotechnology using an in vitro catheterization model (IVCM) to analyze the effect on UTI for a variety of plant extracts and compared the results with data obtained using known antibiotics (Figure 2). In vitro testing of sample viability, antibacterial activity, and characterization of functional extracts were performed to use them as adjuvants in treating urinary tract infections.

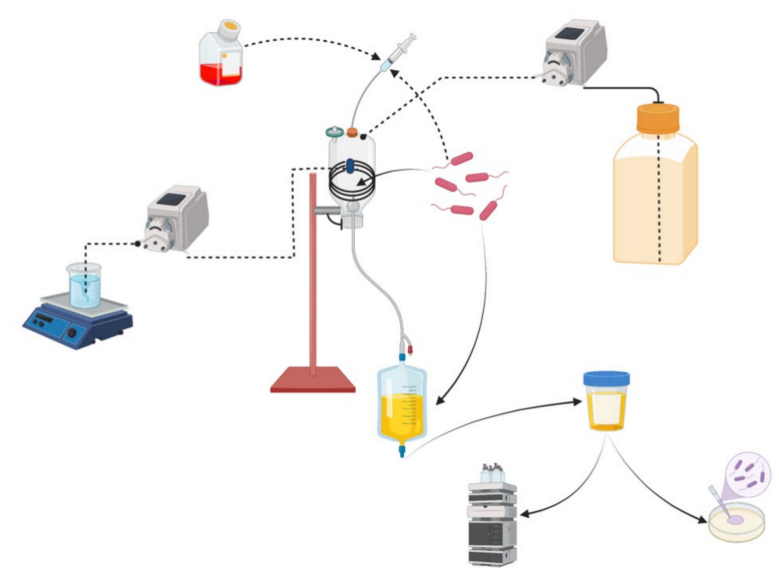

Figure 2. After the update of the constructive model, the redrawn schematic version of the in vitro catheterization model from the Faculty of Biotechnology, UASVM Bucharest. The figure contains the full details of the system, with a heating system made by the authors (left part of the picture). Samples are analyzed by microbiologic and chromatographic methods to fully understand the in vitro simulation [27]. The figure was created with the Biorender app. 
The general operating principle is presented below [23]:

- The peristaltic pump ensured the continuous supply of sterilized artificial urine at a rate of $1 \mathrm{~L}$ per day. The bladder temperature was maintained at $35-37^{\circ} \mathrm{C}$ by a circulatory system that included a peristaltic pump and a ceramic heating plate;

- A urinary catheter was used to drain the bladder. The leftover urine contributed to the inflated balloon's physiological stagnation in a catheterized bladder. A urine catheter was attached to a 'drainage bag'-like effluent collection vessel;

- The bladder had rubber septa ports that facilitated the aseptic inoculation of bacteria of interest. The catheter tip was placed into the bladder and secured by inflating the balloon with $15 \mathrm{~mL}$ of sterile phosphate buffered saline (PBS). Urine flow was started to fill the bladder to the necessary capacity $(80-100 \mathrm{~mL})$ so that the balloon could be covered;

- After that, the flow of urine from the tank was turned off to allow bacteria to be inoculated into the septum port's 'bladder.' To simulate the introduction of contaminating bacteria into the bladder during catheter insertion at the clinical site, approximately $5 \times 10^{7} \mathrm{CFU}$ of $E$. coli were injected into the bladder. This would result in a contaminating bacteria concentration of $5 \times 10^{5} \mathrm{CFU} / \mathrm{mL}$;

- To prevent bacteria from being removed immediately after inoculation, the urine flow was interrupted for one hour and then resumed [28].

\subsection{In Vivo Vision of In Vitro Urinary Tract Models}

Human urothelial models represent a chapter of interest in the current research. In vivo, cells are exposed to urine and create a barrier supplied by nearby cells/tissues. Although urine may be required to differentiate the cells in vitro, it is a harsh environment, and, even in the short term, it may not be the only fluid used. Only part of the urothelium would be exposed to urine in an ideal in vitro model, whereas an appropriate differentiation medium would support the basolateral compartment. This is why advanced urothelial models will benefit from platforms that have porous substrates. The most straightforward implementation would be a transwell system or similar permeable membrane systems [29]. The volume of urine added, the possibility to change urine concentrations over time, and donor characteristics are considered factors (sex, age, and any diseases or disorders that could alter the urine's composition). Fluid flow platforms, which are still being extensively investigated, can be implemented in more advanced models [2].

\section{Management of Recurrent UTI by Non-Antibiotic Plant-Based Prevention and Treatments}

Prophylactic antibiotics therapy is the current standard of care to prevent recurrent UTI in many worldwide guidelines [30]. However, recent UK, European, and US guidelines advise prudent antibiotic prescribing to reduce antimicrobial resistance [31]. The reason is that many studies have confirmed the emergence of antibiotic-resistant UTI pathogens after a few weeks of prophylactic therapy, including multiple drug resistance (MDR). It has been reported that most E. coli urinary isolates have resistance to amoxicillin, while colistin and carbapenem resistance are emerging in Enterobacteriaceae [1]. Moreover, the prophylactic antibiotic treatment remains of doubtful usefulness, and some of the MDR uropathogenic strains will soon be untreatable with the current antibiotics on which UTI-prone patients rely $[1,2]$.

The problem of antimicrobial resistance is recognized as a global public health concern that provokes high financial costs to healthcare systems and is fueled by the overuse of antibiotics. Since 2014 World Health Organization has highlighted that antibiotic resistance in uropathogens is a key pressure point in the global antimicrobial resistance crisis. Therefore, there is an urgent need to understand UTI pathophysiology better and develop innovative products that use non-antibiotic strategies to prevent and treat UTI. A different non-antibiotic approach might provide the optimal treatment to reduce rUTI. A recently 
published comprehensive article discusses the future of non-antibiotic prevention and management of recurrent urinary tract infections [1].

Phytotherapy, alternative medicine based on plant extracts [32], is an essential nonantibiotic strategy that has been used for centuries to prevent or treat different diseases, including UTI [33]. Medicinal plants have long been an excellent place to search for innovative ways to treat human health issues. The biologically active substances present in medicinal plants have evolved to protect the plant from pathogens and, therefore, could prevent/treat human infections [34].

Complementary and alternative plant medicine has been an effective practical approach for treating rUTI, especially as a prophylactic therapy of antibiotics, as both have a synergistic effect. Plant medicines are a realistic option for the long-term prevention of rUTI. They are cost-effective, readily available, safe to use, with fewer reported side effects, and do not induce bacterial resistance. The innovation in prophylactic plant-based treatments, especially for UTI-prone patients with high recurrence rates, should target the bottleneck points of UTI pathogenesis. The bioactive plant molecules used in rUTI treatment must prevent uropathogen adherence to urothelial cells, internalization or biofilm formation, and the production of inhibitory molecules against defensive immune response and modulate the natural microbial community, restoring the microbiome dysbiosis. Moreover, phytotherapy is critical in providing a way to reduce rUTI symptoms without using antibiotics. However, aggressive acute UTI treatment requires antibiotic therapy associated with plant-based therapies that increase the antibiotic effect and the host's immune response.

However, the mechanism of plant medicines used for the treatment of rUTI is still poorly understood. Further studies are required to disclose the potential of all active compounds responsible for pharmaceutical activities and their potential adverse effects, including mutagenic and carcinogenic activities. The antimicrobial effects of plant extracts are attributed to multiple mechanisms: directly killing microbes, interfering with microbial adhesion to epithelial cells and biofilm formation, stopping the multiplication of pathogens, restoring dysbiosis, improving the host protection acting on natural barriers, serving as immunomodulators, or boosting body oxidant status [35]. Therefore, using whole plant extracts is recommended, as the biologically active compounds work synergistically and have different mechanisms of action [36]. In the last years, some reports have enlisted botanicals helpful in preventing and curing UTI and made synopses with the therapeutical potential of medicinal plants for the management of UTI [1-6,36-39].

The present review covers plants with recognized anti-uropathogenic activities and promising medicinal plants that can treat infection recurrence but are less studied $[39,40]$.

\section{Plants Commonly Used in the Treatment of rUTI}

A vast majority of the medicinal plants known in traditional medicine in different areas worldwide have been studied in vitro and in clinical trials for the prophylaxis of UTI or combined treatment with antibiotics. Currently, cranberry is considered the most effective plant extract to prevent rUTI. At the same time, plants with high berberine contents, such as uva-ursi or different Chinese herbs, are frequently prescribed for acute UTI. The review selected only a few well-known plants that have been approved for the treatment of rUTI and discussed studies that confirmed the active compounds responsible for their therapeutic potential.

\subsection{Herbal Chinese Medicine}

The herbal products used in traditional Chinese medicine have been proven efficient to treat UTI symptoms for over 2000 years because they have significant diuretic, antimicrobial, anti-inflammatory, and immune-enhancing activities. Different medicinal herbs have been studied in vitro and in clinical trials for the prophylaxis of active and recurrent UTI or are used in combination with antibiotic treatment. Extensively studied Chinese herbs named Huang Liam (Coptis chinensis Franch) have shown in vitro inhibitory and anti-inflammatory effects against a broad spectrum of uropathogenic strains, including UPEC. These herbs 
contain highly active berberine alkaloid compounds (berberine, coptisine, and palmatine) with specific inhibitory activity against $E$. coli [13]. Antimicrobial substances from Salvia plebeia, a native herb from Asia, have been shown to inhibit the growth of $E$. coli at a minimal inhibitory concentration of $0.25 \mathrm{~g} / \mathrm{mL}$ [29]. Moreover, several clinical trials havee proven that adding Chinese herbs to antibiotic prophylaxis is more effective in reducing rUTI rates, especially in postmenopausal women, but more extensive randomized trials are required. Although different Chinese plant remedies are routinely prescribed in rUTI treatment, Sihra et al., 2018 concluded that high-quality and well-conducted clinical studies should be undertaken [1].

\subsubsection{Arctostaphylos uva-ursi}

Leaf extracts from A. uva-ursi, an herb found in Europe and northern America and named "grape of the bear", obtained Germany's governmental approval for treatment of UTI [6]. The leaves contain flavonoids, tannins, terpenoids, iridoids, and arbutin, a glycoside with recognized antibacterial activity [26]. Uvacin and Uva-E are commercial products based on uva-ursi extracts from leaves and have been reported to be effective in preventing rUTI. However, other herbal formulae with this plant have dose-dependent activities against uropathogens and may serve as an essential adjuvant treatment to antibiotic prophylaxis in reducing rUTI.

\subsubsection{Vaccinium macrocarpon-Cranberry}

Currently, no definitive mechanism of action has been clarified to explain the prophylactic treatment of UTI, but there is much clinical evidence that the berries and cranberrycontaining products can be used as prophylaxis for rUTI [1]. Cranberry is a plant from the family Ericaceae, known as $V$. macrocarpon. It was used by native Americans to treat infections [41]. Other varieties, including V. oxycoccos, a small/bog cranberry, and V. erythrocarpum, a southern mountain cranberry, have also been used to treat UTI because these berries contain many biologically active compounds that are supposed to be responsible for anti-uropathogenic activities [42]. Cranberries contain fructose and A-type proanthocyanidins that have been found to prevent the adhesion of E. coli to uroepithelial cells, and prolonged exposure to cranberry induced a change in the morphology of $E$. coli to the spherical shape that affects adherence [36,43]. Ursolic acid inhibits E. coli biofilm formation, and quinic acid is responsible for the excretion of hippuric acid and acidifies the urine. In contrast, sialic acid has an anti-inflammatory and painkilling effect, but other cranberry components have a complementary or synergistic role that contributes to the antibacterial development $[1,40]$.

Ellura, a proanthocyanidin-rich commercial product from cranberry, is used for its preventive role in rUTI. Recent reviews analyzed the data obtained during clinical trials that have been conducted to assess the efficiency of cranberry extracts/juice/syrup/tablets/capsules in UTI treatment. They concluded that they are mixed results and more significant welldesigned trials are required [1,40]. However, in the case of rUTI, several randomized controlled trials with a large number of participants suggested that cranberry products might be efficient in specific populations (women with rUTI and children). Still, some side effects could occur [1]. An interesting result was reported in a clinical trial when cranberry extract $(500 \mathrm{mg} / \mathrm{kg})$ administered for six months decreased the UTI to the same level as the trimethoprim (100 mg) [44].

\subsection{Promising Medicinal Plants to Treat rUTI}

\subsubsection{P. granatum L.-Pomegranate}

Pomegranate (P. granatum L.) is a fruit-bearing shrub in the Punicacea family, described initially throughout the Mediterranean region but widely cultivated in the present [45]. Pomegranate has been known for centuries for its multiple health benefits, including antimicrobial activities, due to various biologically active substances from all plant parts, including the fruit juice, peel, arils, flowers, and bark $[45,46]$. Different parts of the pomegranate 
(fruit, horns, skin, and seed) have been extracted utilizing an extraction procedure based on maceration with various extraction solvents (water, ethanol, methanol, ethyl acetate, etc.). Aqueous and organic extracts from the fruits and by-products have antibacterial constituents, such as hydrolyzable tannins (punicalagin and penicillins, ellagic acid, and gallic acid) synergized with bioactive flavonols, i.e., myricetin, quercetin, and anthocyanins, e.g., cyanidin-3-glucose and pelargonidin-3-galactose [47,48]. Seed extracts have urobactericidal activity against different $E$. coli clinically isolated from patients suffering from urinary tract infections [49]. The researchers suggested that therapeutic antioxidants and natural glycosides are supposed to act as molecular decoys to prevent the adhesion of pathogenic bacteria from hosting cells, thereby inhibiting future pathogenesis, but further studies are required to confirm it [49]. Pomegranate peel is a waste obtained through juice processing. It contains significant amounts of bioactive compounds (total phenols, flavonoids, anthocyanins, tannins, and proanthocyanidins) with variations between different cultivars and drying processes [50]. The primary polyphenols in pomegranate that have been shown to have antimicrobial, antioxidant, and anti-inflammatory bioactivities are ellagitannins and anthocyanins, which are concentrated in the fruit's peel and kernels. Aqueous pomegranate peel extract's antimicrobial and antioxidant effect against uropathogenic E. coli has recently been reported [51]. The inhibitory activity was dose- and pH-dependent, with a minimum inhibitory concentration value of $0.6 \mathrm{mg} / \mathrm{mL}$ that produced a reduction of up to $80 \%$ of the adhesion index, accompanied by a decrease in motility and ornithine decarboxylation. In comparison, total inhibition was reported at a $1.2 \mathrm{mg} / \mathrm{mL}$ value. Thus, the peel extract inhibits the biofilm formation and cellular adherence of $E$. coli and reduces bacterial motility and the polyamine production that helps bacteria to survive during the oxidative stress produced by some antibiotics (fluoroquinolones, aminoglycosides, and cephalosporins) [51].

Different parts of P. granatum (pericarp, leaves, flowers, and seeds) have antibacterial activities against antibiotic-resistant $E$. coli strains, but the ethanol extract of pericarp has a significant effect on animal E. coli isolates [52]. Another significant result showed by this study is that water extracts were not as active as organic extracts against tested E. coli. In another study, a methanolic section of pomegranate fruit pericarp tested with ciprofloxacin against extended-spectrum $\beta$-lactamase (ESBL)-producing $E$. coli showed an enhancement of ciprofloxacin activity, probably due to the bacterial efflux pump inhibitor activity of the polyphenolic constituents from the extract [53]. However, the isolates exhibiting a high level of ciprofloxacin resistance did not respond to ciprofloxacin-extract combinations, and the authors consider that this result is due to target site modification that is not influenced by plant inhibitor molecules [38].

An aqueous extract of pomegranate leathery exocarp showed antifungal and antibacterial effects, including on E. coli, related to an anti-acetylcholinesterase inhibitory effect and antioxidant activities. This promising antimicrobial effect was compared to the synthetic drug activity. At an extract concentration of $10 \mathrm{mg} / \mathrm{mL}$, the result against $E$. coli was equal to kanamycin. In contrast, the lower concentration of the extract $(5 \mathrm{mg} / \mathrm{mL})$ showed higher bactericidal activity than tetracycline [54].

Pomegranate aril extracts $(30-90 \mu \mathrm{g} / \mathrm{mL}$ ) from six different varieties from Turkey (Mediterranean region) have proven antimicrobial effects on other microorganisms [55], including E. coli DM. The authors demonstrated that the antimicrobial effect of extracts is dependent on the plant cultivar, not on the phenolic content. The most acidic plant variety with the second-highest phenolic content from all varieties tested had the most significant inhibitory effect on E. coli [55].

Ellagic acid is a bioactive tannin from the methanolic extract of pomegranate that inhibits biofilm formation by bacteria Staphylococcus aureus and E. coli [56]. Moreover, it has been proven that pomegranate polyphenols or the interactive effect of different compounds present in the extract may indirectly inhibit quorum-sensing, the signaling mechanism used by bacteria to communicate and form a biofilm [43]. 
Because of the health benefits linked to its polyphenol content, pomegranate extract pills/juice are becoming increasingly popular. They have been acknowledged as an effective plant extract for urinary tract infections [57]. Still, clinical trials that use only pomegranate extracts to prove their efficiency in UTI prevention or treatment are missing. Polyphenols, ellagic acid, anthocyanins, and glycosides are the main bioactive substances that support the use of pomegranate in rUTI prophylaxis, alone or in combination with antibiotic therapy.

\subsubsection{A. melanocarpa (Michx.) Elliott-Black Chokeberry}

Sometimes known as scores, chokeberry fruits are members of the Rosaceae family's Aronia genus. A. melanocarpa (Michx.) Elliott-black chokeberry and A. arbutifolia L.-red chokeberry are the two shrubs species utilized as fruits in the genus (red scab) [58]. The fruit of $A$. melanocarpa (Figure 3 ) is known for its high concentration of bioactive compounds, such as polyphenols with significant antioxidant and antimicrobial effects, which have been studied intensively for the last 15 years [59]. The proanthocyanidin concentration of A. melanocarpa is four times higher than in cranberry, and aronia berries contain a higher dose of quinic acid; both compounds help fight and prevent UTI [60]. Moreover, $100 \mathrm{~g}$ of raw cranberries were scaled at 9584 on the USDA ORAC (oxygen radical absorbance capacity) value scale, with the highest antioxidant capacity from common fruits, while aronia berry was 16,862 [61].

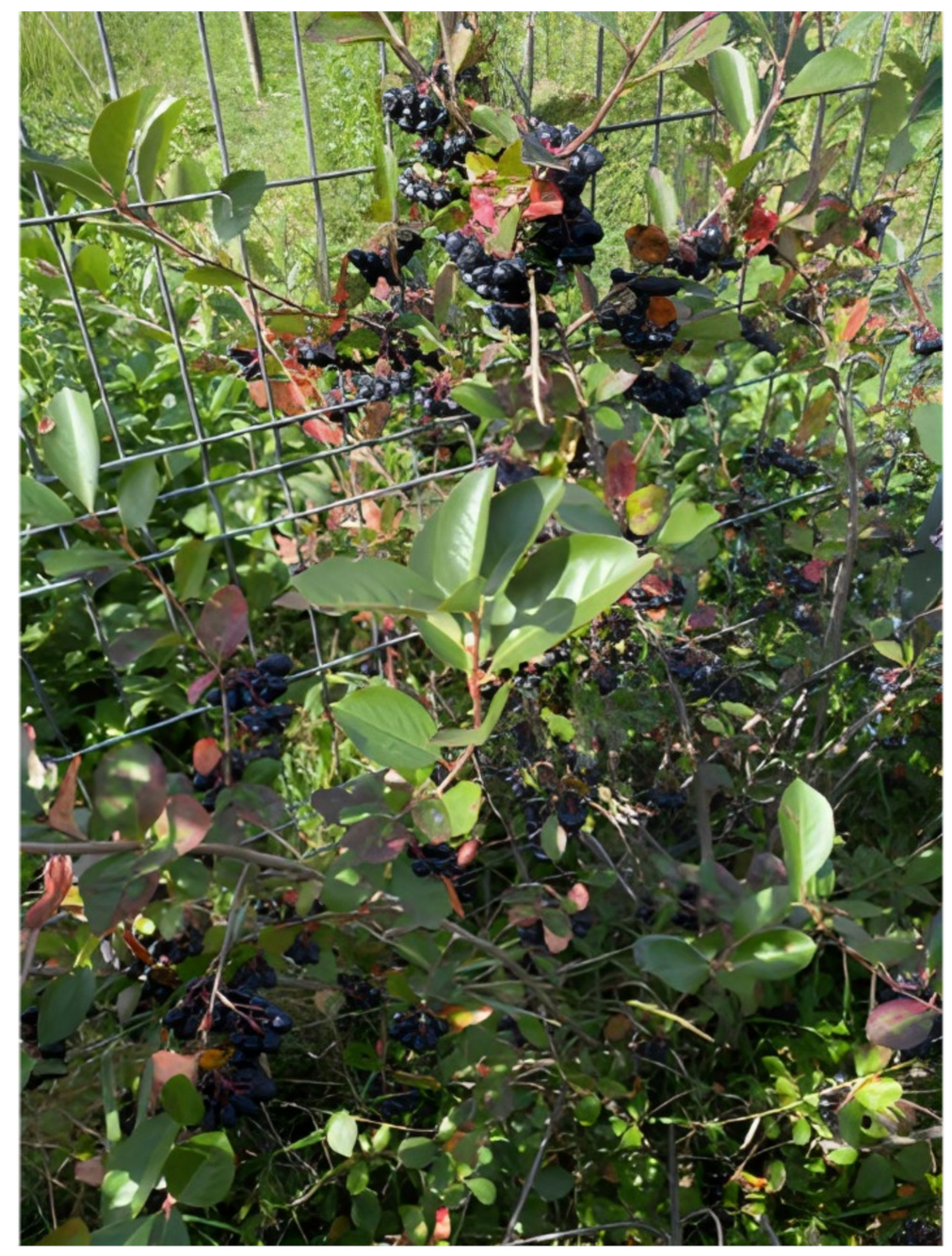

Figure 3. The fruit of A. melanocarpa growing in Ionășeni village, Vârfu Câmpului, Botoșani county, Romania. 
The mechanism of action for anthocyanins from A. melanocarpa proved that at a minimum inhibitory concentration (MIC) of $0.625 \mathrm{mg} / \mathrm{mL}$ and minimum bactericidal concentration of $1.25 \mathrm{mg} / \mathrm{mL}$, anthocyanins compromise the integrity of the E. coli cell wall and membrane, bind directly to the bacterial DNA, and interfere with protein homeostasis [62]. Epicatechin, a proanthocyanidin from Aronia extracts, has been involved in the biofilm formation effect in the case of uropathogenic E. coli CFT073 (ATCC 700928). It supposes that the active substance interferes with quorum-sensing chemotaxis/or mobility genes [63]. Bacteria in a biofilm are often responsible for recurrence and antibiotic treatment failure. Therefore, finding new plants rich in bioactive molecules with anti-biofilm activity, such as epicatechin from $A$. melanocarpa, ellagic acid from $P$. granatum, and ursolic acid from cranberry, is a good non-antitoxic inhibition strategy with a reduced potential for resistance development.

The results of the antibacterial activities of black chokeberry fruit extract are mixed. In a recent study, the leaf aqueous extract had a bacteriostatic effect against $E$. coli and L. monocytogenes, decreasing the growth rate and extending the lag phase [64]. An HPLC analysis showed that Aronia extract contained 15 phenolic compounds and 11 flavonoids, mainly flavonols and hydroxycinnamic acid. The total concentration of phenolic acids $(114.66 \mu \mathrm{g} / \mathrm{mL})$ was higher than that of flavonoids $(93.40 \mu \mathrm{g} / \mathrm{mL})$. However, no clear relationship was found between the influence of the aronia extracts and whether the tested bacteria belonged to the Gram-positive or Gram-negative groups. In another study, a common inhibition effect was noticed for $20 \mu \mathrm{L}$ of black chokeberry leaf extract that reduced the growth of the tested E. coli strain by $23 \%$ [64,65]. Similarly, it has been shown that aqueous and ethanolic extracts of fresh, dried, or frozen fruits have efficacy against Bacillus cereus, S. aureus, and Pseudomonas aeruginosa but did not influence E. coli 332 [66]. In a study, E. coli strains were resistant to extracts from leaves, berries, and stems obtained by subcritical water extraction $[66,67]$. These contradictory results could be explained by differences in the extract preparation method and the tested E. coli strains.

Anthocyanidin-rich extracts obtained as lyophilized powders from mature fruits of A. melanocarpa L., cultivated in the ecological environment in the Eastern Carpathians in Romania, were used to test the synergism-based antibiotic treatment on pathogens from the urinary tract [68]. The extract contained anthocyanins and epicatechin units, and the extraction method had an essential impact on the quantity of each component of the plant extract. The antioxidant activity of the extract was in close relation to the anthocyanidin concentration, and it was noticed that the ethanolic extracts proved to be active against 10 out of the 18 tested strains at doses of $2.5-5 \mathrm{mg} / \mathrm{mL}$. Moreover, a significant inhibition of monoculture biofilm formation of 11 out of all tested strains was reported. Antibiotic disks (amikacin, tetracycline, nitrofurantoin, imipenem, and norfloxacin) supplemented with the extract slowly increased the growth inhibition zone in the case of P. aeruginosa, E. coli, and M. morganii [69]. The synergistic antibiotic extract effect that has been shown for pomegranate and black chokeberry could be explained by the presence in the extract of other secondary metabolites with antibacterial activities or the increase in antibiotic activity due to the existence of active biomolecules from the plant extract (polyphenols, tannins, etc.). In this way, the efficacy of an existing drug could be improved with the help of an inexpensive alternative therapy.

Accurate and reliable clinical evidence about the efficiency of black chokeberry in UTI treatment is missing; only one clinical trial has been found that reported the reduction in UTI frequency after three months of juice administration in a specific population group (residents from six nursing homes) [70]. Polyphenols, anthocyanidins, epicatechin, and quinic acid, with anti-biofilm formation and antioxidant activities, are bioactive substances that raised attention to aronia berries and their role in fighting rUTI. Moreover, A. melanocarpa fruits appear to have more excellent health and wellness benefits, higher antioxidant levels, and fewer side effects than cranberry. 


\subsubsection{C. mas L.-Cornelian Cherry}

The cornelian cherry (C. mas L.) is a member of the Cornaceae family (Cornaceae), found in the wild throughout Europe's central and south-eastern areas and Asia, where fruits have been used for centuries in traditional medicine [71]. The considerable number of anthocyanins in cornelian cherry is linked to the fruits' main pro-health benefits; however, the chemical makeup of C. mas is varied and primarily depends on variety, culture, and environmental and climatic circumstances [72]. Extracts from different parts of the plant revealed broad pharmacological activities. Various studies identified 101 compounds among active biological anthocyanins, flavonoids, iridoids, and vitamin C, especially in the fruits [73]. The highest antimicrobial activity of the C. mas leaf extract was correlated with iridoids, ellagic acid, and ellagitannins, substances that were not detected in A. melanocarpa leaf extract [64]. This study noted the more substantial effect of cornelian cherry leaf extract (1\%) on Gram-negative bacteria compared to Gram-positive bacteria and explained that some interactions that may occur between polyphenols, iridoids, and cell walls, but the results are not in agreement with other data reported in the literature. Biologically active substances from cornelian cherry leaf extract produced morphological changes in bacterial aggregate formation-induced reactive oxygen species with various adverse intracellular effects, including suppressing the DNA gyrase activity that inhibits DNA synthesis [64]. Second-line antibiotics recommended in the therapy of rUTI, such as quinolones, especially ciprofloxacin, have a similar mechanism of action and target DNA gyrase. However, the C. mas bark extract showed moderate antibacterial activity on some bacteria but no effect on others, including E. coli, or on the yeasts C. albicans and R. rubra [74].

Cornelian cherry fruits are non-toxic and safe foods, based on toxicity studies in rat and human models. They can mainly treat diabetes, obesity, atherosclerosis, skin diseases, and gastrointestinal and rheumatic problems [75]. The data in the literature have suggested that polyphenols and iridoids are responsible for the therapeutic benefits of cornelian cherry fruits on many physiological parameters [76]. Moreover, the leaves from C. mas have shown significant anti-inflammatory effects connected with inhibiting aldose reductase, an overexpressed enzyme in many inflammation processes and cancers [77].

The recent trends in herbal medicine open new insights into using $C$. mas in the treatment of rUTI (Table 1). The administration of cornelian cherry tablet (500 mg) for six months in women affected by rUTI decreased dysuria and frequent urination. However, positive urine culture in the group that received C. mas (19\%) compared to the group that received placebo $(33.4 \%)$ was not statistically significant [78]. More research must be conducted to clarify the action mechanism of cornelian cherry extract in rUTI cure. Still, polyphenols, anthocyanidins, iridoids, and vitamin $C$ with antioxidant effects seem to be the active molecules involved. At the same time, clinical trials are necessary to use a combination of plant extract and a combination of plant extract and pre- and probiotics to prove their effectiveness [79]. 
Table 1. Anti-uropathogenic activities of extracts from pomegranate (P. granatum L.), black chockeberry (A. melanocarpa Michx.), and cornelian cherry (C. mas L.).

\begin{tabular}{|c|c|c|c|c|c|}
\hline Plant Name & Extract/Part Used & $\begin{array}{l}\text { Bioactive } \\
\text { Compounds }\end{array}$ & $\begin{array}{c}\text { Name of } \\
\text { Microorganisms Tested (E. coli or } \\
\text { Other Uropathogens) }\end{array}$ & Main Conclusions & Reference \\
\hline \multirow{6}{*}{$\begin{array}{l}\text { Pomegranate } \\
\text { (P. granatum L.) }\end{array}$} & $\begin{array}{l}\text { aril extracts from six pomegranate } \\
\text { varieties grown in the Mediterranean } \\
\text { region of Turkey }\end{array}$ & polyphenols & E. coli DM & $\begin{array}{l}\text { - The most acidic cultivar with the second highest phenolic } \\
\text { content from all varities tested had the greatest inhibitory effect } \\
\text { on E. coli. }\end{array}$ & [40] \\
\hline & leathery exocarp extract & & E. coli Migula & $\begin{array}{l}\text { - The higher concentration of the aqueous extract }(10 \mathrm{mg} / \mathrm{mL}) \\
\text { showed a significant bactericidal effect against } E \text {. coli, equal to } \\
\text { kanamycin, whereas the lower concentration of the extract } \\
(5 \mathrm{mg} / \mathrm{mL}) \text { showed a higher bactericidal activity against } E \text {. coli } \\
\text { than tetracycline. }\end{array}$ & [39] \\
\hline & $\begin{array}{l}\text { fruit pericarp extract } \\
\text { tested in combination with } \\
\text { ciprofloxacint }\end{array}$ & polyphenols & $\begin{array}{l}\text { extended-spectrum } \beta \text {-lactamase (ESBL)-producing E. } \\
\text { coli, which were screened for their resistance profile } \\
\text { against fluoroquinolone antibiotics }\end{array}$ & $\begin{array}{l}\text { - This study demonstrated a synergy of a } \\
\text { ciprofloxacin-methanolic extract combination against ESBL } \\
\text { Gram-negative bacilli. }\end{array}$ & [38] \\
\hline & $\begin{array}{l}\text { extracts from different parts (pericarp, } \\
\text { leaves, flowers, and seeds) }\end{array}$ & & $\begin{array}{l}\text { E. coli type (1), which affected calves and had shown } \\
\text { antibiotic resistance }\end{array}$ & $\begin{array}{l}\text { - The alcoholic extracts revealed different antibacterial activities } \\
\text { against } E \text {. coli type }(1) \text {. } \\
\text { - Pericarp etanol extract had the best antibacterial activity. } \\
\text { - The water and ether petroleum extracts had no } \\
\text { antibacterial effectiveness. }\end{array}$ & {$[37]$} \\
\hline & peel extract & anthocyanins and ellangitannins & E. coli collected from urinary cultures & $\begin{array}{l}\text { - The inhibitory activity was found to be dose- and } \mathrm{pH} \text { - } \\
\text { dependent, with a minimum inhibitory concentration (MIC) } \\
\text { value of } 0.6 \mathrm{mg} / \mathrm{mL} \text { at the } \mathrm{pH} \text { of the aqueous extract (3.5). } \\
\text { - The assay of adhesion carried out at the MIC showed a } \\
\text { reduction of up to } 80 \% \text { of the adhesion index accompanied } \\
\text { with reductions in motility and polyamide production. }\end{array}$ & {$[36]$} \\
\hline & seed extract & $\begin{array}{l}\text { tannins, steroids, terpenes, } \\
\text { coumarins, flavonoids, } \\
\text { andglycosides }\end{array}$ & $\begin{array}{l}\text { uropathogens E. coli, Enterococcus faecalis, S. aureus, and } \\
\text { K. pneumonia }\end{array}$ & $\begin{array}{l}\text { - This study showed urobactericidal activity against different } \\
\text { strains that were clinically isolated from patients suffering from } \\
\text { urinary tract infections. }\end{array}$ & [34] \\
\hline
\end{tabular}


Table 1. Cont.

\begin{tabular}{|c|c|c|c|c|c|}
\hline Plant Name & Extract/Part Used & $\begin{array}{l}\text { Bioactive } \\
\text { Compounds }\end{array}$ & $\begin{array}{l}\text { Name of } \\
\text { Microorganisms Tested (E. coli or } \\
\text { Other Uropathogens) }\end{array}$ & Main Conclusions & Reference \\
\hline \multirow{6}{*}{$\begin{array}{l}\text { Black chockeberry } \\
\text { (A. melanocarpa } \\
\text { Michx.) }\end{array}$} & ripe fruit extracts & $\begin{array}{l}\text { - anthocyanins (cyanidin } \\
\text { 3-galactoside, cyanidin 3- } \\
\text { glucoside, cyanidin 3-arabinoside, } \\
\text { and cyanidin 3- xyloside) } \\
\text { - Epicatechin and its dimers } \\
\text { and trimers }\end{array}$ & $\begin{array}{l}\text { - E. coli ATCC 13202, P. aeruginosa ATCC 27853, E.faecalis } \\
\text { ATCC } 29212 \text { and S. aureus ATCC } 29212 \\
\text { - } 18 \text { clinical isolates from patients with urinary tract } \\
\text { infections (E. coli 2041, E. coli } 1851 \text {, E. coli 1992, } \\
\text { P. aeruginosa 1908, P. aeruginosa 1128, K. pneumoniae 2110, } \\
\text { K. preumoniae 1074, K. pneumoniae 831, } \\
\text { Morganella morganii } 2520 \text {. Acinetobacter baumanii 1908, } \\
\text { A. baumanii } 2329, \text { Enterobacter cloacae 2951, E. faecalis } \\
\text { 2823, E. faecium 2862, E. faecium 2980, E. faecium 2027, } \\
\text { S. aureus 14, and S. aureus } 17\end{array}$ & $\begin{array}{l}\text { - This extract was the most active against one strain of } E . \text { coli } \\
\text { and one of } M \text {. morganii at MIC }(5 \mathrm{mg} / \mathrm{mL}) \text {. } \\
\text { - It inhibited the development of biofilm in the case of an } E . \text { coli } \\
\text { and a M. morganii. } \\
\text { - Antibiotic disks (amikacin, tetracycline, nitrofurantoin, } \\
\text { imipenem, and norfloxacin) supplemented with the extract } \\
\text { slowly increased the growth inhibition zone in the cases of } \\
\text { P. aeruginosa, E. coli, and M. morganii. }\end{array}$ & {$[50]$} \\
\hline & plant extract & anthocyanins & E. coli LWT & $\begin{array}{l}\text { - This extract compromised the integrity of the bacterial cell } \\
\text { wall and membrane, bound directly to the bacterial DNA, and } \\
\text { interfered with protein homeostasis. }\end{array}$ & [44] \\
\hline & $\begin{array}{l}\text { crude extracts, subfractions, and } \\
\text { compounds from aronia }\end{array}$ & epicathechin & $\begin{array}{l}\text { E. coli K12 JM109, and uropathogenic E. coli CFT073 } \\
\text { (ATCC 700928) }\end{array}$ & $\begin{array}{l}\text { - These extracts inhibited bacterial growth of E. coli in vitro. } \\
\text { - They possessed an anti-biofilm formation effect. }\end{array}$ & [45] \\
\hline & $\begin{array}{l}\text { aqueous and ethanolic extracts from } \\
\text { fresh, dried, and frozen fruits. }\end{array}$ & & E. coli MSCL 332 & - No activity against $E$. coli was reported. & [48] \\
\hline & leaves, berries, and stem extracts & & E. coli & - E. coli was one of the most resistant strains. & [49] \\
\hline & leaf extract & & E. coli, & $\begin{array}{l}\text { - E. coli showed the greatest resistance and was reduced by } 23 \% \\
\text { with } 20 \mu \mathrm{L} \text { of aqueous ethanol extract. }\end{array}$ & [47] \\
\hline \multirow[t]{2}{*}{$\begin{array}{l}\text { Cornelian cherry } \\
\text { (C. mas L.) }\end{array}$} & leaf extract & $\begin{array}{l}\text { iridoids, ellagic acid, and } \\
\text { ellagi-tannins, }\end{array}$ & E. coli & $\begin{array}{l}\text { - The extracts acted as bacteriostatic agents. } \\
\text { - C. mas showed higher antimicrobial activity than } \\
\text { A. melanocarpa extract. } \\
\text { - C. mas leaf extract reduced the growth of all Gram-negative } \\
\text { bacteria tested at the lowest concentration ( } 1 \% \text {. } \\
\text { - The authors concluded that some interactions may occur } \\
\text { between different bioactive compounds, explaining the } \\
\text { stronger effect on Gram-negative bacteria in comparison to } \\
\text { Gram-positive bacteria. }\end{array}$ & [46] \\
\hline & bark extract & & E. coli & - The extract did not inhibit the growth of $E$. coli. & [54] \\
\hline
\end{tabular}




\section{Conclusions}

For prevention and long-term treatment of rUTI, plant-based alternatives to antibiotics are appealing choices because they are cost-effective, readily available, safe, with fewer side effects, reduce antimicrobial resistance hazards, and help decrease adverse antibiotic effects and different symptoms. The antimicrobial resistance problem that occurs due to conventional antibiotic treatments has not been reported yet for natural plant remedies that contain a wide range of active phytochemical biomolecules responsible for their beneficial effects. Plant polyphenols, such as anthocyanidins and proanthocyanidins, flavonoids, ellagitannins, and monoterpenoids, such as iridoids, are the main phytoconstituents accountable for the treatment of rUTI. Still, current research only enlisted them, and information about their mechanisms of action is scarce.

Therefore, screening medicinal plants with therapeutic potential for rUTI cure should be conducted, as well as further studies at the molecular level to reveal the chemical composition of all potential compounds responsible for pharmaceutical activities and their mechanisms. Currently, commercial products with cranberry are considered effective plant extracts to prevent rUTI, but new studies proved that other plants with less side effects than cranberry might be considered. Pomegranate (P. granatum L.), black chokeberry ( $A$. melanocarpa Michx.), and cornelian cherry (C. mas L.), illustrated in detail above, have great potential to be used for prevention or in a synergistic antibiotic therapy to cure UTI. The results sustain the opportunity for further studies with these plant extracts that could improve the current treatment, but more scientific evidence and large-scale well-designed clinical trials are required.

The innovation in prophylactic plant-based treatment strategies should target the bottleneck points from UTI pathogenesis and search for molecules that reduce rUTI symptoms without antibiotics and those that increase the host's immune response. Further progress in developing plant-based products to cure rUTI will be supported by the advances in UTI pathogenesis and human-based models to understand their pharmacological activities better.

Author Contributions: Writing, A.M.T.; writing—review and editing; L.D.D. and E.V. All authors have read and agreed to the published version of the manuscript.

Funding: This research received no external funding.

Institutional Review Board Statement: Not applicable.

Informed Consent Statement: Not applicable.

Data Availability Statement: Not applicable.

Acknowledgments: The graphical abstracts in Figures 1 and 2 were created with BioRender.com, last accessed on 28 February 2022. Figure 3 was upscaled, artifacts were removed, and the quality was increased with the Deep Image AI photo enhancer.

Conflicts of Interest: The authors declare no conflict of interest.

\section{References}

1. Sihra, N.; Goodman, A.; Zakri, R.; Sahai, A.; Malde, S. Nonantibiotic prevention, and management of recurrent urinary tract infection. Nat. Rev. Urol. 2018, 15, 750-776. [CrossRef]

2. Murray, B.O.; Flores, C.; Williams, C.; Flusberg, D.A.; Marr, E.E.; Kwiatkowska, K.M.; Charest, J.L.; Isenberg, B.C.; Rohn, J.L. Recurrent Urinary Tract Infection: A Mystery in Search of Better Model Systems. Front. Cell. Infect. Microbiol. 2021, 11, 691210. [CrossRef] [PubMed]

3. Silverman, J.A.; Schreiber, H.L.; Hooton, T.M.; Hultgren, S.J. From Physiology to Pharmacy: Developments in the Pathogenesis and Treatment of Recurrent Urinary Tract Infections. Curr. Urol. Rep. 2013, 14, 448-456. [CrossRef] [PubMed]

4. Lewis, A.J.; Richards, A.C.; Mulvey, M.A. Invasion of Host Cells and Tissues by Uropathogenic Bacteria. Microbiol. Spectr. 2016, 4, 359-381. [CrossRef] [PubMed]

5. Bazzaz, B.S.F.; Fork, S.D.; Ahmadi, R.; Khameneh, B. Deep insights into urinary tract infections and effective natural remedies. Afr. J. Urol. 2021, 27, 6. [CrossRef] 
6. Gatea Kaabi, S.A.; Abdulrazaq, R.A.; Rasool, K.H.; Khassaf, S.A. Western herbal remedies for Urinary Tract infections. Arch. Urol. Res. 2020, 4, 49-60. [CrossRef]

7. Jacobsen, S.M.; Stickler, D.J.; Mobley, H.L.T.; Shirtliff, M.E. Complicated catheter-associated urinary tract infections due to Escherichia coli and Proteus mirabilis. Clin. Microbiol. Rev. 2008, 21, 26-59. [CrossRef]

8. Cortese, Y.J.; Wagner, V.E.; Tierney, M.; Devine, D.; Fogarty, A. Review of Catheter-Associated Urinary tract infections and In Vitro Urinary Tract Models. J. Healthc. Eng. 2018, 2018, 2986742. [CrossRef]

9. Tamadonfar, K.O.; Omattage, S.N.; Spauldine, C.N.; Hultgren, S.J.O.N. Reaching the End of the Line: Urinary Tract Infections. In C. R. Pascale Cossart, Bacteria and Intracellularity. Microbiol. Spectr. 2019, 7, 83-99. [CrossRef]

10. Klein, R.D.; Hultgren, S.J. Urinary tract infections: Microbial pathogenesis, host-pathogen interactions and new treatment strategies. Rev. Nat. Rev. Microbiol. 2020, 18, 211-226. [CrossRef]

11. Storme, O.; Tirán Saucedo, J.; Garcia-Mora, A.; Dehesa-Dávila, M.; Naber, K.G. Risk factors and predisposing conditions for urinary tract infection. Therap. Adv. Urol. 2019, 11, 1756287218814382. [CrossRef] [PubMed]

12. Zaffanello, M.; Malerba, G.; Cataldi, L.; Antoniazzi, F.; Franchini, M.; Monti, E.; Fanos, V. Genetic risk for recurrent urinary tract infections in humans: A systematic review. J. Biomed. Biotechnol. 2010, 2010, 321082. [CrossRef] [PubMed]

13. Godaly, G.; Ambite, I.; Svanborg, C. Innate immunity and genetic determinants of urinary tract infection susceptibility. Curr. Opin. Infect. Dis. 2015, 28, 88-96. [CrossRef] [PubMed]

14. Ragnarsdóttir, B.; Lutay, N.; Grönberg-Hernandez, J.; Köves, B.; Svanborg, C. Genetics of innate immunity and UTI susceptibility. Nat. Rev. Urol. 2011, 8, 449-468. [CrossRef]

15. Kawalec, A.; Zwolińska, D. Emerging Role of Microbiome in the Prevention of Urinary Tract Infections in Children. Int. J. Mol. Sci. 2022, 23, 870. [CrossRef]

16. Yang, S.B.F. Pathophysiology of UTIs. In Female Urinary Tract Infections in Clinical Practice; Yang, S.F.B., Ed.; Springer International Publishing: Berlin/Heidelberg, Germany, 2020; pp. 1-10. Available online: https://link.springer.com/book/10.1007/978-3-03027909-7 (accessed on 24 February 2022).

17. Davenport, M.; Mach, E.K.; Shortliffe, L.M.D.; Banaei, N.; Wang, T.H.; Liao, J.C. New and developing diagnostic technologies for urinary tract infections. Nat. Rev. Urol 2017, 14, 296-310. [CrossRef]

18. Bergeron, M.G.; Ouellette, M. Preventing antibiotic resistance through rapid genotypic identification of bacteria and of their antibiotic resistance genes in the clinical microbiology laboratory. J. Clin. Microbiol. 1998, 36, 2169-2172. [CrossRef]

19. Mitsakakis, K.; Kaman, W.E.; Elshout, G.; Specht, M.; Hays, J.P. Challenges in identifying antibiotic resistance targets for point-of-care diagnostics in general practice. Fut. Microbiol. 2018, 13, 1157-1164. [CrossRef]

20. Stork, C.; Kovács, B.; Rózsai, B.; Putze, J.; Kiel, M.; Dorn, A.; Kovács, J.; Melegh, S.; Leimbach, A.; Kovács, T.; et al. Characterization of Asymptomatic Bacteriuria Escherichia coli Isolates in Search of Alternative Strains for Efficient Bacterial Interference against Uropathogens. Front. Microbiol. 2018, 9, 214. [CrossRef]

21. Köves, B.; Salvador, E.; Grönberg-Hernández, J.; Zdziarski, J.; Wullt, B.; Svanborg, C.; Dobrindt, U. Rare Emergence of Symptoms during Long-Term Asymptomatic Escherichia coli 83972 Carriage without an Altered Virulence Factor Repertoire. J. Urol. 2014, 19, 191. [CrossRef]

22. Ceprnja, M.; Oros, D.; Melvan, E.; Svetlicic, E.; Skrlin, J.; Barisic, K.; Starcevic, L.; Zucko, J.; Starcevic, A. Modeling of Urinary Microbiota Associated With Cystitis. Front. Cell. Infect. Microbiol. 2021, 11, 140. [CrossRef]

23. Georgopoulos, N.T.; Kirkwood, L.A.; Varley, C.L.; MacLaine, N.J.; Aziz, N.; Southgate, J. Immortalisation of normal human urothelial cells compromises differentiation capacity. Eur. Urol. 2011, 60, 141-149. [CrossRef]

24. Baker, S.C.; Shabir, S.; Southgate, J. Biomimetic urothelial tissue models for the in vitro evaluation of barrier physiology and bladder drug efficacy. Mol. Pharm. 2014, 11, 1964-1970. [CrossRef] [PubMed]

25. Hatina, J.; Schulz, W.A. Stem cells in the biology of normal urothelium and urothelial carcinoma. Neoplasma 2012, 59, 728-736. [CrossRef] [PubMed]

26. DyStar Colours Distribution GmbH. Mixtures of Disperse Dyes. U.S. Patent US8906116B2, 9 December 2014.

27. Vamanu, E.; Dinu, L.D.; Luntraru, C.M.; Suciu, A. In Vitro Coliform Resistance to Bioactive Compounds in Urinary Infection, Assessed in a Lab Catheterization Model. Appl. Sci. 2021, 11, 4315. [CrossRef]

28. Chua, R.Y.R.; Lim, K.; Leong, S.S.J.; Tambyah, P.A.; Ho, B. An in-vitro urinary catheterization model that approximates clinical conditions for evaluation of innovations to prevent catheter-associated urinary tract infections. J. Hosp. Infect. 2017, 97, 66-73. [CrossRef] [PubMed]

29. Flaherty, R.A.; Lee, S.W. Implementation of a Permeable Membrane Insert-based Infection System to Study the Effects of Secreted Bacterial Toxins on Mammalian Host Cells. J. Vis. Exp. 2016, 114, e54406. [CrossRef]

30. Dadgostar, P. Antimicrobial Resistance: Implications and Costs. Infect. Drug Resist. 2019, 12, 3903-3910. [CrossRef]

31. Machowska, A.; Stålsby Lundborg, C. Drivers of Irrational Use of Antibiotics in Europe. Int. J. Environ. Res. Public Health 2018, 16, 27. [CrossRef]

32. Foxman, B.; Buxton, M. Alternative approaches to conventional treatment of acute uncomplicated urinary tract infection in women. Curr. Infect. Dis. Rep. 2013, 15, 124-129. [CrossRef]

33. Sofowora, A.; Ogunbodede, E.; Onayade, A. The role and place of medicinal plants in the strategies for disease prevention. Afr. J. Trad. Complement. Alter. Med. 2013, 10, 210-229. [CrossRef] [PubMed] 
34. Terlizzi, M.E.; Gribaudo, G.; Maffei, M.E. UroPathogenic Escherichia coli (UPEC) Infections: Virulence Factors, Bladder Responses, Antibiotic, and Non-antibiotic Antimicrobial Strategies. Front. Microbiol. 2017, 8, 1566. [CrossRef] [PubMed]

35. Belkaid, Y.; Hand, T.W. Role of the microbiota in immunity and inflammation. Cell 2014, 157, 121-141. [CrossRef] [PubMed]

36. Gadisa, E.; Tadesse, E. Antimicrobial activity of medicinal plants used for urinary tract infections in pastoralist community in Ethiopia. BMC Complement. Med. Ther. 2021, 21, 74. [CrossRef] [PubMed]

37. Shaheen, G.; Akram, M.; Jabeen, F.; Ali Shah, S.M.; Munir, N.; Daniyal, M.; Riaz, M.; Tahir, I.M.; Ghauri, A.O.; Sultana, S.; et al. Therapeutic potential of medicinal plants for the management of urinary tract infection: A systematic review. Clin. Exp. Pharmacol. Physiol. 2019, 46, 613-624. [CrossRef]

38. Das, S. Natural therapeutics for urinary tract infections-a review. Future Pharm. J. Sci. 2020, 6, 64. [CrossRef]

39. Peng, M.M.; Fang, Y.; Hu, W.; Huang, Q. The pharmacological activities of compound salviplebeia granules on treating urinary tract infection. J. Ethnopharmacol. 2010, 129, 59-63. [CrossRef]

40. Cela-López, J.M.; Camacho Roldán, C.J.; Gómez-Lizarraga, G.; Martínez, V. A Natural Alternative Treatment for Urinary Tract Infections: Itxasol@, the Importance of the Formulation. Molecules 2021, 26, 4564. [CrossRef]

41. Sarecka-Hujar, B.; Szulc-Musioł, B. Herbal Medicines-Are They Effective and Safe during Pregnancy? Pharmaceutics 2022, 14, 171. [CrossRef]

42. Brown, P.N.; Turi, C.E.; Shipley, P.R.; Murch, S.J. Comparisons of large (Vaccinium macrocarpon Ait.) and small (Vaccinium oxycoccos L., Vaccinium vitis-idaea L.) cranberry in British Columbia by phytochemical determination, antioxidant potential, and metabolomic profiling with chemometric analysis. Planta Med. 2012, 78, 630-640. [CrossRef]

43. Howell, A.B.; Foxman, B. Cranberry juice and adhesion of antibiotic-resistant uropathogens. JAMA 2002, 287, 3082-3083. [CrossRef] [PubMed]

44. McMurdo, M.E.; Argo, I.; Phillips, G.; Daly, F.; Davey, P. Cranberry or trimethoprim for the prevention of recurrent urinary tract infections? A randomized controlled trial in older women. J. Antimicrob. Chemother. 2009, 63, 389-395. [CrossRef] [PubMed]

45. Montefusco, A.; Durante, M.; Migoni, D.; De Caroli, M.; Ilahy, R.; Pék, Z.; Helyes, L.; Fanizzi, F.P.; Mita, G.; Piro, G.; et al. Analysis of the Phytochemical Composition of Pomegranate Fruit Juices, Peels and Kernels: A Comparative Study on Four Cultivars Grown in Southern Italy. Plants 2021, 10, 2521. [CrossRef] [PubMed]

46. Howell, A.B.; D'Souza, D.H. The pomegranate: Effects on bacteria and viruses that influence human health. Evid.-Based Complementary Altern. Med. eCAM 2013, 2013, 606212. [CrossRef]

47. Fahmy, H.; Hegazi, N.; El-Shamy, S.; Farag, M.A. Pomegranate juice as a functional food: A comprehensive review of its polyphenols, therapeutic merits, and recent patents. Food Funct. 2020, 11, 5768-5781. Available online: https://pubs.rsc.org/en/ content/articlelanding/2020/fo/d0fo01251c (accessed on 24 February 2022). [CrossRef]

48. Pirzadeh, M.; Caporaso, N.; Rauf, A.; Shariati, M.A.; Yessimbekov, Z.; Khan, M.U.; Imran, M.; Mubarak, M.S. Pomegranate as a source of bioactive constituents: A review on their characterization, properties and applications. Crit. Rev. Food Sci. Nutr. 2021, 61, 982-999. [CrossRef]

49. Das, S.; Panigrahi, S.; Panda, P. Antiurobacterial activity of Punica granatum L. seed extract. Eur. J. Med. Plants 2018, $22,1-12$. [CrossRef]

50. Abdel-Salam, F.F.; El_deen Moharram, Y.G.; El-Zalaki, E.M. Characterization of Wastes from Pomegranate (Punica granatum L.) Juice and Its Use as a Functional Drink. Egypt J. Food Sci. 2018, 46, 91-100. Available online: https://ejfs.journals.ekb.eg/article_ 46941.html (accessed on 24 February 2022).

51. Zam, W.; Khaddour, A. Anti-virulence effects of aqueous pomegranate peel extract on E. coli urinary tract infection. Progr. Nutr. 2017, 19, 98-104. [CrossRef]

52. AlFadel, F.; Allaham, S.A.; Alkhatib, R. The Anti-Bacterial Activity of Various Parts of Punica granatum on Antibiotics Resistance Escherichia coli. Int. J. Pharmacog. Phytochem. Res. 2014, 6, 79-85. Available online: https://brief.land/jjm/articles/56335.html (accessed on 24 February 2022).

53. Dey, D.; Debnath, S.; Hazra, S.; Ghosh, S.; Ray, R.; Hazra, B. Pomegranate pericarp extract enhances the antibacterial activity of ciprofloxacin against extended-spectrum $\beta$-lactamase (ESBL) and metallo- $\beta$-lactamase (MBL) producing Gram-negative bacilli. Food Chem. Toxicol. 2012, 50, 4302-4309. [CrossRef] [PubMed]

54. Elshafie, H.S.; Caputo, L.; De Martino, L.; Sakr, S.H.; De Feo, V.; Camele, I. Study of Bio-Pharmaceutical and Antimicrobial Properties of Pomegranate (Punica granatum L.) Leathery Exocarp Extract. Plants 2021, 10, 153. [CrossRef] [PubMed]

55. Duman, A.D.; Ozgen, M.; Dayisoylu, K.S.; Erbil, N.; Durgac, C. Antimicrobial Activity of Six Pomegranate (Punica granatum L.) Varieties and Their Relation to Some of Their Pomological and Phytonutrient Characteristics. Molecules 2009, 14, 1808-1817. [CrossRef]

56. Bakkiyaraj, D.; Nandhini, J.R.; Malathy, B.; Pandian, S.K. The anti-biofilm potential of pomegranate (Punica granatum L.) extract against human bacterial and fungal pathogens. Biofouling 2013, 29, 929-937. [CrossRef] [PubMed]

57. Vlachojannis, C.; Zimmermann, B.F.; Chrubasik-Hausmann, S. Efficacy and safety of pomegranate medicinal products for cancer. eCAM 2015, 2015, 258598. [CrossRef] [PubMed]

58. Kokotkiewicz, A.; Jaremicz, Z.; Luczkiewicz, M. Aronia plants: A review of traditional use, biological activities, and perspectives for modern medicine. J. Med. Food. 2010, 13, 255-269. [CrossRef]

59. Valcheva-Kuzmanova, S.V.; Belcheva, A. Current knowledge of Aronia melanocarpa as a medicinal plant. Folia Med. 2006, 48, 11-17. 
60. Smeriglio, A.; Barreca, D.; Bellocco, E.; Trombetta, D. Proanthocyanidins and hydrolysable tannins: Occurrence, dietary intake and pharmacological effects. Br. J. Pharmacol. 2017, 174, 1244-1262. [CrossRef]

61. Available online: https:/ / handle.nal.usda.gov/10113/43336 (accessed on 17 February 2022).

62. Deng, H.; Zhu, J.; Tong, Y.; Kong, Y.; Tan, C.; Wang, M.; Wan, M.; Meng, X. Antibacterial characteristics and mechanisms of action of Aronia melanocarpa anthocyanins against Escherichia coli. LWT 2021, 150, 112018. [CrossRef]

63. Bräunlich, M.; Økstad, O.A.; Slimestad, R.; Wangensteen, H.; Malterud, K.E.; Barsett, H. Effects of Aronia melanocarpa constituents on biofilm formation of Escherichia coli and Bacillus Cereus. Molecules 2013, 18, 14989-14999. [CrossRef]

64. Efenberger-Szmechtyk, M.; Nowak, A.; Czyżowska, A.; Kucharska, A.Z.; Fecka, I. Composition and Antibacterial Activity of Aronia melanocarpa (Michx.) Elliot, Cornus mas L. and Chaenomeles superba Lindl. Leaf Extracts. Molecules 2020, 25, 2011. [CrossRef]

65. Tian, Y.; Puganen, A.; Alakomi, H.L.; Uusitupa, A.; Saarela, M.; Yang, B. Antioxidative and antibacterial activities of aqueous ethanol extracts of berries, leaves, and branches of berry plants. Food Res. Int. 2018, 106, 291-303. [CrossRef]

66. Liepina, I.; Nicolajeva, V. Antimicrobial activity of extracts from fruits of Aronia melanocarpa and Sorbus aucuparia. Environ. Exp. Biol. 2013, 11, 195-199. Available online: https:/ / americanaronia.org/antimicrobial-activity-extracts-fruits-aronia-melanocarpasorbus-aucuparia/ (accessed on 24 February 2022).

67. Cvetanovi'c, A.; Zengin, G.; Zekovi'c, Z.; Švarc-Gaji'c, J.; Raži 'c, S.; Damjanovi 'c, A.; Maškovi 'c, P.; Miti 'c, M. Comparative in vitro studies of the biological potential and chemical composition of stems, leaves and berries Aronia melanocarpa's extracts obtained by subcritical water extraction. Food Chem. Toxicol. 2018, 121, 458-466. [CrossRef]

68. Dorneanu, R.; Cioanc, O.; Chifiriuc, O.; Albu, E.; Tuchilu, C.G.; Mircea, C.; Salamon, I.; Hancianu, M. Synergic benefits of Aronia melanocarpa anthocyanin-rich extracts and antibiotics used for urinary tract infections. Farmacia 2017, 65, 778-783. Available online: https: / / farmaciajournal.com/issue-articles/synergic-benefits-of-aronia-melanocarpa-anthocyanin-rich-extracts-andantibiotics-used-for-urinary-tract-infections / (accessed on 24 February 2022).

69. Bräunlich, M.; Slimestad, R.; Wangensteen, H.; Brede, C.; Malterud, K.E.; Barsett, H. Extracts, anthocyanins and procyanidins from Aronia melanocarpa as radical scavengers and enzyme inhibitors. Nutrients 2013, 5, 663-678. [CrossRef] [PubMed]

70. Handeland, M.; Grude, N.; Torp, T.; Slimestad, R. Black chokeberry juice (Aronia melanocarpa) reduces incidences of urinary tract infection among nursing home residents in the long term-a pilot study. Nutr. Res. 2014, 34, 518-525. [CrossRef] [PubMed]

71. Kazimierski, M.; Regula, J.; Molska, M. Cornelian cherry (Cornus mas L.)-characteristics, nutritional and pro-health properties. Acta Sci. Pol. Technol. Aliment. 2019, 18, 5-12. [CrossRef]

72. Bayram, H.M.; Ozturkcan, S.A. Bioactive components and biological properties of cornelian cherry (Cornus mas L.): A comprehensive review. J. Funct. Foods 2020, 75, 104252. [CrossRef]

73. Dinda, B.; Dinda, M.; Dinda, S.; Kyriakopoulos, M.A.; Markopoulos, C.; Thomaidis, S.N.; Velegraki, A.; Zoumpourlis, V. Cornus mas L. (cornelian cherry), an important European and Asian traditional food and medicine: Ethnomedicine, phytochemistry and pharmacology for its commercial utilization in drug industry. J. Ethnopharmacol. 2016, 193, 670-690. [CrossRef]

74. Dulger, B.; Gonuz, A. Antimicrobial activity of some Turkish medicinal plants. Pak. J. Biol. Sci. 2004, 7, 1559-1562. [CrossRef]

75. Danielewski, M.; Matuszewska, A.; Nowak, B.; Kucharska, A.Z.; Sozański, T. The Effects of Natural Iridoids and Anthocyanins on Selected Parameters of Liver and Cardiovascular System Functions. Oxid. Cell Longev. 2020, 2020, 2735790. [CrossRef] [PubMed]

76. Sozański, T.; Kucharska, A.Z.; Rapak, A.; Szumny, D.; Trocha, M.; Merwid-Ląd, A.; Dzimira, S.; Piasecki, T.; Piórecki, N.; Magdalan, J.; et al. Iridoid-loganic acid versus anthocyanins from the Cornus mas fruits (cornelian cherry): Common and different effects on diet-induced atherosclerosis, PPARs expression and inflammation. Atherosclerosis 2016, 254, 151-160. [CrossRef] [PubMed]

77. Szczepaniak, O.M.; Kobus-Cisowska, J.; Kusek, W.; Przeor, M. Functional properties of Cornelian cherry (Cornus mas L.): A comprehensive review. Eur. Food Res. Technol. 2019, 245, 2071-2087. [CrossRef]

78. Dadkhah, N.; Shirani, M.; Etemadifar, S.; Mirtalebi, M. The effect of Cornus mas in preventing recurrent urinary tract infections in women'. Adv. Herb. Med. 2017, 3, 67-76. Available online: https://naldc.nal.usda.gov/catalog/43336 (accessed on 24 February 2022).

79. Pugliese, D.; Acampora, A.; Porreca, A.; Schips, L.; Cindolo, L. Effectiveness of a novel oral combination of D-Mannose, pomegranate extract, prebiotics and probiotics in the treatment of acute cystitis in women. Arch. Ital. Urol. Androl. 2020, 92, 34-38. [CrossRef] 